\title{
Implementación de los Compliance Programs y sus efectos de exclusión 0 atenuación de responsabilidad penal de los sujetos obligados. Actualidad a partir de la Ley 30424, el Decreto Legislativo 1352 y el Proyecto de Reglamento de la Ley 30424
}

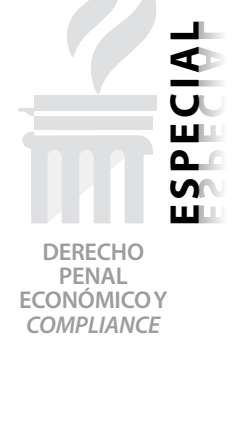

\author{
Luis Miguel Reyna Alfaro*
}

Abogado por la Universidad San Martín de Porres. Doctor en Derecho por la Universidad de Granada. Experto universitario en Criminología por la UNED.

SUMARIO:

I. Planteamiento del problema.

II. Responsabilidad Penal de las Personas Jurídicas. Presente y futuro en el derecho penal peruano.

III. El Compliance.

1. Antecedentes.

2. Contenido del Compliance.

3. Compliance y cultura empresarial.

4. Los Compliance Programs.

IV. La significación dogmática de la implementación de programas de cumplimiento normativo en el contexto de la RPPJ.

1. El caso español —antes de la reforma de 2015-.

2. El caso español —después de la reforma de 2015-.

3. El caso peruano.

4. El modelo de prevención adecuado.

V. Validación criminológica del Compliance como sendero hacia el cual podría evolucionar la dogmática de la RPPJ.

VI. Conclusiones.

* Este trabajo constituye una versión actualizada al 10.06.2018 del trabajo contenido en Ambos/ Caro/ Malarino: Lavado de activos, $453 \mathrm{ss}$. El artículo fue recibido con fecha 12-06-18. 


\title{
RESUMEN:
}

El cumplimiento normativo constituye un tópico de innegable actualidad. Su traslado inicial desde el bussiness ethics hacia el derecho corporativo y luego hacia el derecho penal determina la necesidad de reconocer su capacidad de rendimiento. En nuestro análisis procuramos proponer una valoración inicial de la significación jurídico penal de la implementación de programas de cumplimiento de cara a la posible fundamentación criminológica de su utilización, una arista escasamente reconocida en nuestros países de conocida tradición antiempirica.

Palabras clave: Implementación, programas de cumplimiento, exclusión, atenuación, persona jurídica.

\begin{abstract}
:
Compliance is a topic of undeniable topicality. His initial transfer from bussiness ethics to corporate law and then to criminal law determines the need to recognize his capacity for performance. In our analysis we try to propose an initial assessment of the penal legal significance of the implementation of Compliance programs in the face of the possible criminological foundation of its use, an edge barely recognized in our countries of well-known anti-empirical tradition.

Keywords: Implementation, Compliance programms, exclusion, mitigation, legal person.
\end{abstract}

\section{PLANTEAMIENTO DEL PROBLEMA}

La singular actualidad que vienen teniendo dentro de la dogmática penal los denominados programas de cumplimiento normativo o Compliance programs se viene observando especialmente, aunque no exclusivamente, en relación a la marcha triunfal de la Responsabilidad Penal de la Persona Jurídica —en adelante, la "RPPJ"—-1 y la prevención del lavado de activos y financiamiento del terrorismo.

En efecto, en la medida que los Sistemas de Prevención del LA/FT —en adelante, "SPLAFT"- se dirigen hacia los sujetos obligados ${ }^{2}$ y estos son, en su mayoría aunque no exclusivamente, personas jurídicas, es lógico que se aborden los efectos de la implementación de Compliance programs sobre la responsabilidad - penal o sui generis, según se asuma- de la persona jurídica. Por otra parte, no puede obviarse el hecho que la idea del Compliance ha sido desarrollada con mayor extensión y detalle en el contexto del SPLAFT.

El análisis que se realizará en torno a los efectos de la implementación de programas de cumplimiento normativo tendrá sustento en los apor-

1. Expresión que Schünemann utiliza en relación al impacto del procedimiento penal norteamericano en el mundo. SCHÜNEMANN, Bernd. ¿Crisis del procedimiento penal? ¿Marcha triunfal del procedimiento penal norteamericano en el mundo?, traducción de Silvina Bacigalupo y Lourdes Baza, en el mismo, Temas actuales y permanentes del Derecho penal después del Milenio. Madrid: Tecnos, 2002, p. 288 y ss. Es sintomático que precisamente en el ámbito ahora examinado se haga referencia a la americanización de la discusión. NIETO MARTíN, Adán. "El programa político criminal del corporate goverment". En BAIGUN, David y GARCÍA RIVAS, Nicolás, Delincuencia económica y corrupción. Su prevención penal en la Unión Europea y el Mercosur. Buenos Aires: Ediar, 2006, p. 468 y ss.; o se sostenga que la RPPJ es un escenario donde se refleja el acercamiento entre el derecho penal europeo continental y norteamericano. HEFENDEHL, Roland. "La responsabilidad penal corporativa". En: REYNA ALFARO, Luis (Coord.), Nuevas tendencias del Derecho penal económico y de la empresa. Lima, Ara, 2005. p. 419.

Es de advertir que la implementación de programas de cumplimiento normativo tiene también efectos en la delimitación de los espacios de responsabilidad individual, al establecer las competencias de cada actor dentro de la estructura empresarial, lo que tiene efectos a nivel de la imputación normativa del comportamiento. Dicho ámbito de trascendencia de los programas de cumplimiento no será examinado en esta oportunidad.

2. Expresión que alude a los sujetos obligados a informar a la UIF- Perú la información referida en la Ley 27693, indicados en el artículo 3 de la Ley 29038. 
tes de la criminología que es precisamente uno de los espacios menos explorados por la doctrina jurídica que ha examinado el tema de la RPPJ y su fundamentación.

En este análisis, se incorporan ciertas reflexiones derivadas de la introducción de la Ley 30424 - "Ley que regula la responsabilidad administrativa de las personas jurídicas por el delito de cohecho activo transnacional" - y el Decreto Legislativo 1352 - "Decreto Legislativo que amplía la responsabilidad administrativa de las personas jurídicas" - así como del Proyecto de Reglamento de la Ley 30424.

\section{RESPONSABILIDAD PENAL DE LAS PERSONAS JURÍDICAS. PRESENTE Y FUTURO EN EL DERECHO PENAL PERUANO}

Hasta antes de la promulgación de la Ley 30424 y el Decreto Legislativo 1352 - de recién puesta en rigor-, se descartaba en nuestro país la RPPJ. Esto dado el marco corte individual de las estructuras dogmáticas sobre las que descansa el Código Penal —en adelante, "CP"—. En ese sentido, la base normativa para dicha afirmación se ubica en el artículo 11 del CP: "Son delitos y faltas las acciones y omisiones dolosas o culposas penadas por la ley"; que reconoce como presupuesto del hecho punible la existencia de una acción jurídico penalmente relevante ${ }^{3}$. Esta afirmación -la de irresponsabilidad penal de las personas jurídicas - tenía consenso en la doctrina peruana dominante ${ }^{4}$.

Sin embargo, como vaticinamos en oportunidad anterior ${ }^{5}$, la marcha triunfal de la RPPJ ${ }^{6}$ llegó a nuestro país expresada en la Ley 30424 y el

3. En esa misma línea de ideas: GRACIA MARTíN, Luis. "La cuestión de la responsabilidad penal de las propias personas jurídicas". En: FRANCISCO, H. y ATAHUAMAN, Jhuliana (coords.), Derecho Penal económico y de la empresa. Lima: Idemsa, 2013, p. 223; RODRÍGUEZ MOURULLO, Gonzalo. "Hacia la responsabilidad penal de las personas jurídicas en el Código Penal español". En: Estudios de derecho penal económico, Madrid: Civitas, 2009, p. 277; TERRADILLOS BASOCO, Juan. Derecho penal de la empresa. Madrid: Trotta, 1995, p. 45; VILLAVICENCIO TERREROS, Felipe. Derecho Penal. Parte General. Lima: Grijley, 2006, p. 268; HURTADO POZO, Jose y MEINI MÉNDEZ, Iván. “Las personas jurídicas frente al Derecho Penal peruano". En: HURTADO POZO, José; DEL ROSAL BLASCO, Bernardo; SIMONS VALLEJO, Rafael (coords.). La responsabilidad criminal de las personas jurídicas. Una perspectiva comparada. Madrid: Tirant lo Blanch, 2001, p. 83; MEINI MÉNDEZ, Iván. La responsabilidad penal de las personas jurídicas. Lima: Fondo Editorial de la Pontificia Universidad Católica del Perú, 1999, p. 109 y ss.; REYNA ALFARO, Luis Miguel: "Panorama actual de la responsabilidad penal de las empresas". En: Revista Peruana de Derecho de la Empresa № 68. Lima: 2009, p. 78 y ss.; REYNA ALFARO, Luis Miguel. Manual de Derecho penal económico y de la empresa. Lima: Gaceta Jurídica, 2002. p. 117; URTECHO BENITES, Santos. Criminalidad de empresa. Lima: Forum, 2006, p. 70; MONTOYA MANFREDI, Ulises. Responsabilidad de los directores de las sociedades anónimas. Lima: Imprenta de la Universidad Nacional Mayor de San Marcos, 1975, p. 29 y ss.; BALCARCE, Fabián y CESANO, José Daniel. "Reflexiones sobre la responsabilidad penal de las personas jurídicas en la república argentina". En: BALCARCE, Fabián (director). Derecho penal económico. Parte General, tomo I. Córdoba: Mediterránea, 2003, pp. 187-189; CESANO, José Daniel. "Problemas de responsabilidad de la empresa". En: LÓPEZ MESA, Marcelo y CESANO, José Daniel. El abuso de la personalidad jurídica de las sociedades mercantiles. Córdoba: Depalma, 2000, p. 276.

4. Sosteniendo también que la legislación penal peruana recusa la responsabilidad penal de las personas jurídicas: TIEDEMANN, Klaus. "Corporate criminal liability as a third track". En BRODOWSKI, Dominik, ESPINOZA DE LOS MONTEROS DE LA PARRA, Manuel y TIEDEMANN, Klaus y VOGEL, Joachim (Eds.). Regulating corporate criminal liability. Nueva York: Springer, 2014, p. 13; VILLAVICENCIO TERREROS, Felipe. Derecho Penal. Parte General. Lima: Grijley, 2006, p. 268; BRAMONT ARIAS, Luis. Derecho penal peruano (visión histórica). Lima: Ediciones Jurídicas UNIFE, 2004, p. 539; PEÑA CABRERA, Raúl. Tratado de Derecho Penal. Parte General. Lima: Grijley, 1999, p. 698; GARCÍA RADA, Domingo. Sociedad anónima y delito. Lima: 1972, p. 9.

5. REYNA ALFARO, Luis Miguel. Manual de Derecho penal económico y de la empresa. Lima: Gaceta Jurídica, 2002, pp. 455-456.

6. Paradigmáticas y significativas resultan las reformas penales producidas en sendos países de habla hispana: España —Ley Orgánica 5/2010, de 22 de junio—; Chile — Ley 20393, del 25 de noviembre de 2009—; Colombia 
Decreto Legislativo 1352, normas que han significado un vuelco en el estado de las cosas al establecer un sistema de responsabilidad penal de la persona jurídica que deberá coexistir con el de responsabilidad penal individual?

En contra de lo propuesto por algún sector de la doctrina ${ }^{8}$, consideramos que la Ley 30424 reconoce una responsabilidad sui generis penal/ administrativa pero no estrictamente administrativa - que debe concurrir con la diseñada para las personas naturales. La opción en favor de considerar a la Ley 30424 como una de naturaleza sui generis se extrae, al contrario de lo que podría pensarse, de su semántica. No obstante que la Ley 30424 lleva un rótulo que llevaría a afirmar - a partir de consideraciones semánticas - su naturaleza meramente "administrativa", la terminología utilizada por el legislador -es decir, también la semánticaevoca continuamente y formula referencias a una serie de instituciones de naturaleza jurídico penal ${ }^{9}$, lo que aunado a la configuración de un sistema de individualización de las consecuencias jurídicas que rememora también al correspondiente a las personas naturales ${ }^{10}$ y la fijación de la competencia - para su imposición-en los jueces penales, permite coincidir con aquel sector de la doctrina que entiende que la Ley 30424 supone un mero fraude de

—Ley 1474 del 2011—; Ecuador —Código Orgánico Integral Penal, artículo 49-y Venezuela —Ley Penal del Ambiente, del 02 de mayo de 2012-. Véase también las referencias hechas en Bacigalupo: Compliance, 63/ 95, a los desarrollos de la legislación danesa, francesa, eslovena, inglesa y el Corpus Juris europeo, que dan cuenta del estado de las cosas en Europa, y el vaticinio de que esta será una "realidad generalizada tarde o temprano en el Derecho penal europeo continental y probablemente también en el derecho penal latinoamericano". Un examen del derecho comparado en torno a este tema puede verse, entre otros, en: TIEDEMANN, Klaus. "Corporate criminal liability as a third track". En BRODOWSKI, Dominik, ESPINOZA DE LOS MONTEROS DE LA PARRA, Manuel y TIEDEMANN, Klaus y VOGEL, Joachim (Eds.). Regulating corporate criminal liability. Nueva York: Springer, 2014, p. 13; TIEDEMANN, Klaus. "Responsabilidad penal de las personas jurídicas". En: Temas de Derecho Penal Económico y Ambiental. Lima: Idemsa, 1999, pp. 199 y ss.; ENGELHART, Marc. "Corporate criminal liability from a comparative perspective". En: BRODOWSKI, Dominik, ESPINOZA DE LOS MONTEROS DE LA PARRA, Manuel, TIEDEMANN, Klaus y VOGEL, Joachim (Eds.). Regulating corporate criminal liability. Nueva York: Springer, 2014, p. 56; ZUGALDÍA ESPINAR, José Miguel. La responsabilidad criminal de las personas jurídicas, de los entes sin personalidad y de sus directivos. Valencia: Tirant lo Blanch, 2012, pp. 30-32; DE MIGUEL, Iñigo. "La responsabilidad penal de las personas jurídicas: Un estudio desde la perspectiva de la política criminal a partir de la modificación del Código Penal español". En: ROMEO CASABONA, Carlos María, FLORES MENDOZA, Fátima (Eds.). Nuevos instrumentos jurídicos en la lucha contra la delincuencia económica y tecnológica. Granada: Comares, 2012, p. 419.

7. Destacan la necesidad de estructurar un sistema de imputación penal propio para las personas jurídicas: BAJO FERNÁNDEZ, Miguel y BACIGALUPO SAGGESE, Silvina. Derecho penal económico. Madrid: CEURA, 2001, pp. 133 y ss.; en la doctrina latinoamericana: BAIGUN, David. La responsabilidad penal de las personas jurídicas (Ensayo de un nuevo modelo teórico). Buenos Aires: Depalma, 2000, pp. 32 y ss.; RIGHI, Esteban. Los delitos económicos. Buenos Aires: Ad Hoc, 2000, pp. 140 y ss.

8. En ese sentido GÓMEZ-JARA DÍEZ, Carlos. Compliance y responsabilidad penal de las personas jurídicas en el Perú. Directrices para su interpretación. Lima: Pacífico, 2018, pp. 23-24, quien refiere - pese a reconocer que el legislador penal peruano no ha explicado los motivos para calificar la Ley $N^{\circ} 30424$ como de "responsabilidad administrativa"- que una vez decantado el legislador por esa vía, debe respetarse dicha opción, sin perjuicio del surgimiento de propuestas de lege ferenda.

9. Por ejemplo, la referencia a "circunstancias atenuantes" y "circunstancias agravantes" o la mención a las "eximentes" de responsabilidad.

10. Basta con confrontar las normas sobre "individualización de las medidas administrativas" y las de "suspensión de la ejecución de las medidas administrativas" de los artículos 15 y 16 de la Ley 30424 con las normas sobre individualización judicial de la pena y suspensión de la ejecución de la pena de los artículos muy similar al indicado en los artículos 45-A y 57 del Código Penal. 
etiquetas $^{11}$. Ahora, esta afirmación inicial, en virtud de la cual reconocemos elementos penales en la naturaleza de la responsabilidad de la persona jurídica prevista en la Ley 30424, no impide aceptar elementos administrativos derivados no solo de la semántica utilizada por el legislador -en la calificación de la ley como de responsabilidad administrativa y en el tratamiento de los modelos de prevención conforme se avizora del Proyecto de Reglamento de la Ley 30424 - sino también por la cercanía existente entre el régimen sancionatorio previsto en la Ley 30424 y el correspondiente a las consecuencias accesorias aplicables a las personas jurídicas del artículo 105 del Código Penal.

No es posible sostener que estamos frente a una regulación cerrada pues queda aún pendiente de promulgación el Reglamento de la Ley 30424 cuyo Proyecto viene siendo socializado en los portales informáticos del Ministerio de Justicia y Derechos Humanos, por lo que las reflexiones aquí expuestas serán, seguramente, complementadas a futuro.

\section{EL COMPLIANCE}

\section{Antecedentes.}

Los Compliance programs son herramientas del denominado "Compliance". Ambos conceptos deben su irrupción a los contenidos de las $\mathrm{Fe}$ - deral Sentencing Guidelines ${ }^{12}$, circunstancia que constituye, además, un referente constante en los desarrollos de la legislación y la doctrina de nuestros países.

El Compliance tiene antecedentes en la incorporación de la idea del good corporate citizenship - buen ciudadano corporativo-y que, conforme alude Laufer, tendría su génesis normativa en la Foreign Corrupt Practices Act norteamericana de $1977^{13}$. A fines de la década de los setenta, se plantearon en Norteamérica una serie de propuestas de reforma legislativa orientadas al corporate governance. Un punto de quiebre, sin embargo, lo constituyó el primer borrador de los "Principles of corporate governance and structure: Analysis and recommendations" elaborado por el American Law Institute en 1982 y que generó un impacto significativo en la comunidad empresarial norteamericana que veía cómo un grupo de profesores de Derecho establecía estándares legales para la gestión de la empresas ${ }^{14}$.

El paso siguiente en la evolución norteamericana viene conformado por la implementación de la Sentencing Commission establecida por la Sentencing Reform Act de 1984 y que introdujo los lineamientos para establecer responsabilidad penal de las empresas en un contexto en el que las condenas impuestas en sus contras sufrían de una notoria ausencia de uniformidad $^{15}$. El enfoque de las guidelines se orientó a

11. ATAHUAMAN PAUCAR, Jhuliana. "La fundamentación de la responsabilidad penal del compliance officer a través de su especial posición de garante. A propósito de la Ley que regula la responsabilidad administrativa de las personas jurídicas". En COCA, Ivo, URIBE, Alfredo, ATAHUAMAN, Jhuliana y REYNA, Luis (Coords.). Compliance y responsabilidad penal de las personas jurídicas. Distrito Federal: Flores Editor, 2017, p. 239.

12. TIEDEMANN, Klaus. "El derecho comparado en el desarrollo del Derecho penal económico". En: ARROYO ZAPATERO, Luis y NIETO MARTÍN, Adán (directores). El Derecho penal en la era Compliance. Madrid: Tirant lo Blanch, 2013, p. 37; ENGELHART, Marc. "Corporate criminal liability from a comparative perspective". En: BRODOWSKI, Dominik, ESPINOZA DE LOS MONTEROS DE LA PARRA, Manuel, TIEDEMANN, Klaus y VOGEL, Joachim (Eds.). Regulating corporate criminal liability. Nueva York: Springer, 2014, p. 64.

13. LAUFER, William S. Corporate bodies and guilty minds. The failure of corporate criminal liability. Chicago: The University of Chicago Press, 2006, p. 30.

14. Ibíd., p. 31.

15. Ibíd., p. 31. 
establecer las pautas de una organizational due diligence — diligencia debida organizacional-.

Otro paso trascendente se produjo a través de la Blue Ribbon Commission on Defense Managment en 1986. La denominada Packard Commision instaurada para investigar una serie de fraudes en el sector defensa, propuso en su reporte final la necesidad de insistir en el autogobierno corporativo, comprometiendo a los integrantes de la industria a implementar códigos de conducta. Esta Comisión no cambió las reglas impuestas por las guidelines sino que las reforzó ${ }^{16}$.

El impacto de las guidelines sobre las personas jurídicas llevó a estas a plantear una fuerte oposición — planteada a modo de lobby empresarial- lo que derivó en la incorporación de una serie de circunstancias atenuantes de la RPPJ que son expresión evidente de lo que entendemos hoy como Compliance. En efecto, las guidelines ponen a consideración una serie de factores que tienen efectos atenuantes de la RPPJ: (i) El delito se produjo sin el conocimiento de quien ejerce control sobre la organización; (ii) el delito se produjo a pesar de existir un significativo programa de cumplimiento; (iii) La empresa reportó pronta y voluntariamente el delito; (iv) La empresa, luego de descubierto el delito, tomo medidas razonables para remediar el daño, disciplinar a los responsables y evitar la reincidencia ${ }^{17}$.

Se introdujo de ese modo una estrategia de carrot and stick —zanahoria y palo- : Las sanciones contra las personas jurídicas se incrementaron y, seguidamente, se optó por introducir criterios de cumplimientos normativos como factores definitorios de la intensidad de la san- ción. En ese contexto, las guidelines introdujeron criterios para establecer la medida de la culpabilidad teniendo como factores: (i) el nivel de involucramiento o tolerancia de la empresa en la actividad criminal concreta; (ii) antecedentes; (iii) record de infracciones; (iv) intención de obstruir la actividad de la justicia (v) mantenimiento de un programa de Compliance efectivo; y, (vi) la voluntad de autoreportar, cooperar y aceptar la responsabilidad ${ }^{18}$.

A partir de las guidelines las empresas pretenden estar in Compliance with the Guidelines con lo cual comienza a reconocerse la relación del concepto de Compliance con el de due diligence en la medida que el objetivo de las sentencing guidelines es delimitar el due diligence como pauta de comportamiento empresarial que impone obligaciones éticas y legales a las empresas y sus agentes ${ }^{19}$.

Posteriormente la Sarbanes Oxley en 2002, tras el escándalo Enron, se dirigió a enfrentar las debilidades de los sistemas internos de control y la ausencia de independencia de los órganos de control corporativo del directorio, a través del reforzamiento de los deberes de revelación de información por parte de las empresas ${ }^{20}$.

Finalmente, las modificaciones a las sentencing guidelines del 2004 han tenido por propósito introducir pautas dirigidas hacia las empresas, las entidades regulatorias, a la Fiscalía y a los Tribunales de los criterios para reconocer cuando nos encontramos ante un effective Compliance program. Estos cambios se han dirigido esencialmente a reconocer: (i) la importancia, en términos preventivos, de que las empresas promuevan una cultura organizacional orientada al

\footnotetext{
16. Ibíd., p. 32.

17. Ibíd., p. 33.

18. Ibíd., p. 34.

19. Ibíd., p. 35.

20. Ibíd., p. 39.
} 
cumplimiento de la ley; (ii) que la implementación de una organización orientada al due diligence requiere de la intervención de componentes de los niveles superiores de la empresa que se involucren en los programas de cumplimiento normativo; (iii) que las organizaciones empresariales realicen esfuerzos razonables para no incorporar dentro de sus estructuras trascendentes a quienes conozcan o deban saber que tienen antecedentes de infracciones a la ley $u$ otras conductas inconsistentes con los contenidos de los programas de cumplimiento ${ }^{21}$.

\section{Contenido del Compliance.}

El Compliance, no obstante, parte del reconocimiento de que la criminalidad de empresa se produce en un contexto tan variado como variados son los rubros en que esta se desarrolla. Esta circunstancia provoca la coexistencia de subsistemas normativos que pretenden la prevención de los diversos riesgos empresariales. Desde esa perspectiva, por citar un ejemplo bastante común, tendremos que las empresas que se dedican a la actividad minera deben involucrarse con los subsistemas normativos destinados a prevenir los riesgos medioambientales — Ley General del Ambien- te-, riesgos contra la salud y seguridad de los trabajadores - Ley de Seguridad y Salud en el Trabajo-, riesgos de desvío de los insumos y productos químicos fiscalizados para el tráfico de drogas - Ley de control de insumos químicos y productos fiscalizados-, riesgos de corrupción - $\mathrm{CP}$ - etc. Esto ha llevado - como indica Bacigalupo 22 - a que la idea tradicional de riesgo del negocio de la empresa haya variado y se deje de entender solamente como riesgo económico - posibilidades de competencia exitosa en el mercado- y se incorpore en esa idea del riesgo de responsabilidades normativas. Precisamente, la forma de evitar que los riesgos de responsabilidad normativa adquieran realidad es mediante el cumplimiento de la ley.

Lo antes indicado no debe llevar al error de reducir el sentido del Compliance a la idea de que en el ejercicio de su actividad las empresas deben ajustarse al Derecho ${ }^{23}$. El Compliance trasciende a esa noción básica haciendo referencia-como se aprecia- a todo un conjunto de medidas de organización empresarial destinadas a prevenir la aparición de riesgos jurídicamente relevantes orientando la actuación de los miembros de la empresa a favor del cumplimiento de la juridicidad ${ }^{24}$.

21. Ibíd., p. 65.

22. BACIGALUPO ZAPATER, Enrique. Compliance y Derecho penal. Navarra: Aranzadi, 2011, p. 22.

23. Deficiencia en que incurre ENGELHART, Marc. "Corporate criminal liability from a comparative perspective". En: BRODOWSKI, Dominik, ESPINOZA DE LOS MONTEROS DE LA PARRA, Manuel, TIEDEMANN, Klaus y VOGEL, Joachim (Eds.). Regulating corporate criminal liability. Nueva York: Springer, 2014, p. 61; y que es correctamente advertida por COCA VILA, Ivo. "¿Programas de cumplimiento como forma de autorregulación regulada?”. En: SILVA SÁNCHEZ, Jesús María (director). Criminalidad de empresa y compliance. Prevención y reacciones corporativas. Barcelona: Atelier, 2013, p. 54. La idea del cumplimiento de la ley es, además, consustancial a la propia idea del contrato social conforme señala GREEN, Stuart. Lying, cheating and stealing. A moral theory of white collar crime. New York: Oxford University Press, 2006, p. 115.

24. BACIGALUPO ZAPATER, Enrique, Op. Cit., p. 30; COCA VILA, Ivo, Op. Cit., p. 54; MONTANER FERNÁNDEZ, Raquel. "La estandarización alemana de los sistemas de gestión de cumplimiento: Implicaciones jurídico penales". En: SILVA SÁNCHEZ, Jesús María (director). Criminalidad de empresa y compliance. Prevención y reacciones corporativas. Barcelona: Atelier, 2013, p. 143. Debe, sin embargo, reconocerse un cierto grado de imprecisión conceptual en torno a los alcances del Compliance y su contenido. Sobre este aspecto, Sieber destaca los alcances de una investigación realizada en el 2001 en torno al concepto del corporate governance y la falta de consenso dentro de un grupo de empresas alemanas respecto al contenido del Compliance; al respecto: SIEBER, Ulrich. "Programas de compliance en el Derecho penal de la empresa. Una nueva concepción para controlar la criminalidad económica". Traducción de Manuel Abanto. En ARROYO ZAPATERO, Luis y NIETO MARTÍN, Adán (directores). El Derecho penal en la era Compliance. Madrid: Tirant lo Blanch, 2013, p. 67. 


\section{Compliance y cultura empresarial.}

El Compliance tiene su enfoque central en la organización empresarial que debe ser construida en el contexto de una cultura empresaria ${ }^{25}$ orientada al cumplimiento de las normas jurídicas mediante la imposición de valores, códigos, reglas $^{25}$ y procedimientos intraempresariales orientados a la prevención de la criminalidad así como su revelación y efectiva sanción ${ }^{26}$. Surge aquí una simbiosis natural entre los contenidos de la ética de los negocios - Business Ethics - y los de la responsabilidad social, con los contenidos del Compliance ${ }^{27}$.

Esta cultura se manifiesta fundamentalmente a través del comportamiento de los funcionarios u órganos a cargo de la gestión o management empresarial así como de los encargados de la vigilancia y que tiene por efecto predisponer a los diversos actores del conglomerado empresarial a actuar en concordancia con los postulados normativos ${ }^{28}$ incluso en contraposición de los fines consustanciales a la actividad empresarial —obtención de valor para los accionistas- ${ }^{29}$.
Para ello, el Compliance empresarial introduce, por un lado, sistemas internos de comunicación que permitan el conocimiento, a diversos niveles de la estructura empresarial - bottom up y top down-, de información asociada a los riesgos cuya prevención se pretende; y, por otro lado, estructura sistemas de supervisión y sanción que permitan identificar los factores de riesgo, que establezca medidas orientadas a mitigar y eliminarlos, y que establezcan mecanismos sancionatorios oportunos y eficaces para dar respuesta a los casos en los que los riesgos empresariales no hayan sido contenidos ${ }^{30}$.

En este punto, no obstante, es importante dejar en claro que el propósito del Compliance no es el de evitar que se produzcan riesgos derivados de la actividad de empresa, sino que estos no superen los márgenes tolerados socialmente ${ }^{31}$.

\section{Los Compliance programs.}

Los Compliance programs constituyen instrumentos orientados a lograr el objetivo del Compliance empresarial. Los Compliance programs

25. Al respecto GÓMEZ-JARA DÍEZ, Carlos. "Fundamentos de la responsabilidad penal de las personas jurídicas". En: BAJO FERNÁNDEZ, Miguel, FEIJOO SÁNCHEZ, Bernardo y GÓMEZ JARA DIEZ, Carlos. Tratado de responsabilidad penal de las personas jurídicas. Madrid: Civitas/ Thomson Reuters, 2012, p. 114; COCA VILA, Ivo. Op. Cit., p. 56; MONTANER FERNÁNDEZ, Raquel. Op. Cit. p. 148.

26. COCA VILA, Ivo. Op. Cit., p. 55; SIEBER, Ulrich. Op. Cit., p. 70.

27. BACIGALUPO ZAPATER, Enrique. Op. Cit., p. 63; ENGELHART, Marc. Op. Cit., p. 66; NIETO MARTíN, Adán. "El programa político criminal del corporate goverment (Derecho penal de la empresa y gobierno corporativo)". En BAIGUN, David y GARCÍA RIVAS, Nicolás (Directores). Delincuencia económica y corrupción. Su prevención penal en la Unión Europea y el Mercosur. Tucumán: Ediar, 2006, p. 25. Aunque algunos autores, CARBONELL MATEU, Juan Carlos. "Responsabilidad penal de personas jurídicas: Reflexiones en torno a su 'dogmática' y al sistema de la reforma de 2010". En Cuadernos de Política Criminal N 101. Madrid: 2010, p. 13., cuestionen la incorporación de matices éticos en la cuestión de la responsabilidad penal de las personas jurídicas, es de advertir que la asunción de componentes de los Business Ethics se fundamenta en términos de prevención y protección de bienes jurídicos y no en términos de confirmación o fidelidad al Derecho, como propone GARCÍA CAVERO, Percy. Criminal Compliance. Lima: Palestra, 2014, p. 22.

28. MONTANER FERNÁNDEZ, Raquel. Op. Cit., p. 148.

29. BACIGALUPO ZAPATER, Enrique. Op. Cit., p. 33.

30. BACIGALUPO ZAPATER, Enrique. Op. Cit., p. 100; COCA VILA, Ivo. Op. Cit., pp. 58-60.

31. LASCURAÍN, Juan Antonio. "Compliance, debido control y unos refrescos". En: ARROYO ZAPATERO, Luis y NIETO MARTíN, Adán (directores). El Derecho penal en la era Compliance. Madrid: Tirant lo Blanch, 2013, p. 125. 
-o, en español, programas de cumplimientoson cuerpos normativos empresariales a través del cuales se implementan y regulan los sistemas internos de gestión de riesgos, incorporando procedimientos destinados a dicho fin ${ }^{32}$.

Como es evidente, en la medida que el objeto de los programas de cumplimiento es el de gestionar adecuadamente los riesgos de la empresa, es necesario que existan mecanismos destinados a identificar y tasar los riesgos más significativos de la empresa, la idea del conocimiento del negocio resulta fundamental en la medida que este llevará a determinar cuáles son las medidas necesarias para contener los riesgos del negocio ${ }^{33}$.

Su significación, además de estar vinculada a la incorporación de pautas preventivas y sancionatorias, está asociada a la estructura de la organización empresarial y en la delimitación de las funciones y competencias que corresponde a cada uno de los agentes dentro la empresa ${ }^{34}$. De ese modo, los Compliance programs evitarán los estados de organizada irresponsabilidad de todos $^{35}$ a los que la doctrina hace referencia para denunciar los efectos, en términos de impunidad, de la estructuración empresarial compleja.

Ahora, un dato trascendente de cara al análisis de la capacidad de rendimiento de los Compliance programs en un sistema de imputación penal - o cuasi penal- de las personas jurídicas es el reconocer, como señala Ivo Coca Vila, que no existe un modelo de programa de cumplimiento de validez general ${ }^{36}$. En ese sentido, el antes acotado conocimiento del negocio resultará un factor trascendente para reconocer la efectividad del programa de cumplimiento corporativo como mecanismo idóneo de control de riesgos. Este elemento permitirá distinguir los programas de cumplimiento meramente estéticos o cosméticos —window-dressing Compliance programs - de aquellos que si cumplen con su finalidad $y$, por tanto, revelan un afán cierto y real por parte de la persona jurídica de contener los riesgos derivados de sus actividades. No es de extrañar que, en el objetivo de lograr esa distinción, ciertas legislaciones, como la italiana y la chilena ${ }^{37}$, hayan

32. COCA VILA, Ivo. Op. Cit., p. 60.

33. Examinando la variada normativa asociada a la valoración del riesgo en materia de corrupción: AIOLFI, Gemma. "Mitigating the risks of corruption through collective action". En: BRODOWSKI, Dominik, ESPINOZA DE LOS MONTEROS DE LA PARRA, Manuel, TIEDEMANN, Klaus y VOGEL, Joachim (Eds.). Regulating corporate criminal liability. Nueva York: Springer, 2014, p. 126.

34. MONTANER FERNÁNDEZ, Raquel. Op. Cit., p. 148.

35. SCHÜNEMANN, Bernd. Delincuencia empresarial: Cuestiones dogmáticas y de política criminal. Traducción de Beatríz Spinola y Margarita Valle. Buenos Aires: Fabián Di Placido, 2004, p. 24. Precisamente el fenómeno de organizada irresponsabilidad de todos ha sido uno de los factores que han llevado a la introducción en España de un modelo de RPPJ; así SILVA SÁNCHEZ, Jesús María. "La responsabilidad penal de las personas jurídicas en Derecho Español". En SILVA SÁNCHEZ, Jesús María (Director). Criminalidad de empresa y compliance. Prevención y reacciones corporativas. Barcelona: Atelier, 2013, p. 18; cercano, aludiendo a la difusión de responsabilidad en el ámbito de la criminalidad económica, GREEN, Stuart. Op. Cit., p. 26.

36. COCA VILA, Ivo. Op. Cit., p. 61.

37. Ley italiana 231: "Pueden ser adoptados -los programas de cumplimiento- sobre la base de códigos de comportamiento redactados por asociaciones representativas de los entes, que garanticen las exigencias señaladas, comunicados al Ministerio de Justicia, el que, de acuerdo con los Ministerios competentes, podrá formular observaciones sobre la idoneidad de los modelos para prevenir los delitos". Ley chilena 20393: "4) Supervisión y certificación del sistema de prevención de los delitos.

a) El encargado de prevención, en conjunto con la Administración de la Persona Jurídica, deberá establecer métodos para la aplicación efectiva del modelo de prevención de los delitos y su supervisión a fin de detectar y corregir sus faIlas, así como actualizarlo de acuerdo al cambio de circunstancias de la respectiva entidad. b) Las personas jurídicas podrán obtener la certificación de la adopción e implementación de su modelo de prevención de delitos. En el certifi- 
impuesto la necesidad de acreditación de los programas de cumplimiento.

El propósito de esta exigencia se relaciona con la necesidad de evitar que los Compliance programs sean utilizados indiscriminada e indebidamente como escudos protectores de la RPP ${ }^{38}$. Esa circunstancia, por cierto, fue antes advertida en los Estados Unidos de Norteamérica en el que, tras la abrupta irrupción de una suerte de mercado de Compliance programs, las empresas no dudaban en intervenir como adquirientes en la medida que de ese modo se sometían a menor escrutinio y control y por lo tanto a menor responsabilidad, con lo que el negocio resultaba más que favorable ${ }^{39}$.

\section{LA SIGNIFICACIÓN DOGMÁTICA DE LA IMPLEMENTACIÓN DE PROGRAMAS DE CUMPLIMIENTO NORMATIVO EN EL CONTEXTO DE LA RPPJ}

No le falta razón a Gómez-Jara Díez cuando refiere que los sistemas de responsabilidad penal de las personas jurídicas se construyen sobre el eje de los modelos de prevención ${ }^{40}$. Es que en aquellos países donde se ha incorporado la RPPJ se han incorporado - como regla general- cláusulas legislativas que proporcionan significación a la introducción efectiva de programas de cumplimiento normativo, sea de cara a la posible atenuación de responsabilidad penal de la empresa, sea de cara a la exclusión de responsabilidad de los mismos ${ }^{41}$. Nuestra Ley 30424 no resulta ser una excepción pues ha incorporado cláusulas similares.

Para fines didácticos analizaremos dicha cuestión en la legislación española para abordar posteriormente el tratamiento de la eximente en la regulación penal peruana.

\section{El caso español —antes de la reforma de 2015-.}

Para reconocer la trascendencia de esta cuestión, basta con recordar la discusión española respecto a los alcances del artículo 31bis del

cado constará que dicho modelo contempla todos los requisitos establecidos en los numerales 1), 2) y 3) anteriores, en relación a la situación, tamaño, giro, nivel de ingresos y complejidad de la persona jurídica. Los certificados podrán ser expedidos por empresas de auditoría externa, sociedades clasificadoras de riesgo u otras entidades registradas ante la Superintendencia de Valores y Seguros que puedan cumplir esta labor, de conformidad a la normativa que, para estos efectos, establezca el mencionado organismo fiscalizador. c) Se entenderá que las personas naturales que participan en las actividades de certificación realizadas por las entidades señaladas en la letra anterior cumplen una función pública en los términos del artículo 260 del Código Penal".

Sobre esta última: MATUS ACUÑA, Jean. "La certificación de los programas de cumplimiento". En: ARROYO ZAPATERO, Luis y NIETO MARTíN, Adán (Directores). El Derecho penal en la era Compliance. Madrid: Tirant lo Blanch, 2013, p. 145.

38. SCHÜNEMANN, Bernd. "La responsabilidad penal de las empresas y sus órganos directivos en la Unión Europea", traducción de Mariana Sacher. En: BAJO FERNÁNDEZ, Miguel (director). Constitución Europea y Derecho Penal Económico. Madrid: Editorial Universitaria Ramón Areces, 2006, p. 154.

39. LAUFER, William. Op. Cit., p. 101.

40. GÓMEZ-JARA DÍEZ, Carlos. Compliance y responsabilidad penal de las personas jurídicas en el Perú. Directrices para su interpretación. Lima: Pacífico, 2018, p. 26.

41. Este tipo de cláusulas se observan en el CP suizo - artículo 102.2 introducido por Ley de 13 de diciembre de 2002- en la que se hace referencia a la omisión de "medidas organizativas", la legislación penal italiana —Decreto Legislativo 231- que alude a los "criterios de organización del ente", e incluso en la japonesa; al respecto: BACIGALUPO ZAPATER, Enrique, Op. Cit., p. 102; SIEBER, Ulrich. Op. Cit., p. 64. Examina dicha exigencia en relación al caso chileno: MATUS ACUÑA, Jean. "Presente y futuro de la responsabilidad penal de las personas jurídicas por los delitos cometidos por sus directivos y empleados". En: Derecho penal, criminología y política criminal en el cambio de siglo. Santiago de Chile: Editorial Jurídica de Chile, 2011, p. 308. 
$\mathrm{CP}$-antes de la reforma producida a través de la Ley Orgánica № 1/2015 del 30 de marzo-. Este dispositivo, reconocía efectos atenuantes de la RPPJ cuando la persona jurídica haya implementado, previo al inicio del juicio oral, de "medidas eficaces para prevenir y descubrir los delitos que en el futuro pudieran cometerse con los medios o bajo la cobertura de la persona jurídica". Esta cláusula planteaba una serie de cuestiones problemáticas relacionadas con las limitaciones del mencionado artículo 31bis del CP español al restringir la aplicación de la atenuante a los casos en que la implementación de los programas de cumplimiento normativo sea realizada "con posterioridad a la comisión del delito y a través de sus representantes legales".

La primera cuestión trascendente asociada al contenido del mencionado artículo 31bis del CP español tenía que ver con los efectos de la implementación de programas de cumplimiento normativo antes de la realización del hecho punible objeto de procesamiento penal.

En efecto, en la medida que el texto legal establece efectos de atenuación de RPPJ a los casos de implementación de Compliance programs con posterioridad a la comisión del delito ${ }^{42}$, se discutía si era posible proponer efectos eximentes de RPPJ en aquellos casos en los que los programas de cumplimiento normativo fueron implementados antes de la comisión del delito.
Esta posición, fue progresivamente teniendo mayores niveles de aceptación en la medida que existe una predisposición de la doctrina por relacionar la RPPJ con el Compliance y se observan esbozos de estructuración de una teoría del delito de las personas jurídicas en las que el Compliance se propone como elemento delimitador del injusto o como el factor determinante de la culpabilidad de la persona jurídica ${ }^{43}$.

Sobre esto último, es notoria la vinculación - al menos parcial- al modelo de culpabilidad empresarial por defectos de organización que propician que no haya sido posible generar una cultura empresarial ${ }^{44}$ que permita implementar los debidos controles dentro de los diversos niveles de la empresa y que sirva como contención eficaz de la criminalidad económica ${ }^{45}$. Una posición de este tipo tenía en el caso español sustento normativo - ya incluso antes de la reforma de 2015- debido a la referencia hecha en el párrafo segundo del apartado 1 del artículo 31bis del CP de que el delito se haya cometido "por no haberse ejercido sobre ellos - los agentes de la persona jurídica - el debido control atendidas las concretas circunstancias del caso" ${ }^{\prime \prime 6}$.

La imposición de una pena contra la persona jurídica se encontrará plenamente justificada - desde esta visión de la culpabilidad de empresa - no solo cuando la persona jurídica

42. La que funcionaría, según indica BACIGALUPO ZAPATER, Enrique, Op. Cit., p. 111, como una modalidad de compensación parcial de la culpabilidad de la empresa.

43. Una visión general se aprecia en COCA VILA, Ivo. Op. Cit., p. 63. Haciendo referencia a la fundamentación de la responsabilidad administrativa de la persona jurídica en la infracción de los deberes organizativos de la empresa: SIEBER, Ulrich. Op. Cit., p. 88. - "El cumplimiento de las medidas apropiadas de compliance se vuelve así en un criterio jurídico central que decide sobre la imputación del delito a la empresa"—.

44. En esta línea, GÓMEZ-JARA DÍEZ, Carlos. "Fundamentos de la responsabilidad penal de las personas jurídicas". En: BAJO FERNÁNDEZ, Miguel, FEIJOO SÁNCHEZ, Bernardo y GÓMEZ JARA DIEZ, Carlos. Tratado de responsabilidad penal de las personas jurídicas. Madrid: Civitas/ Thomson Reuters, 2012, p. 172.

45. BACIGALUPO ZAPATER, Enrique, Op. Cit., p. 99; similares: ZUGALDÍA ESPINAR, José Miguel. Op. Cit., p. 97; ENGELHART, Marc. Op. Cit., p. 62.

46. SILVA SÁNCHEZ, Jesús María: "La responsabilidad penal de las personas jurídicas en Derecho Español". En Silva Sánchez, Jesús María (Director). Criminalidad de empresa y compliance. Prevención y reacciones corporativas. Barcelona: Atelier, 2013, p. 31. 
carece de un sistema de prevención de riesgos sino cuando habiendo sido adoptado no se ha implementado suficientemente. La vigencia efectiva del programa de cumplimiento, como indica Gómez-Jara:

"simboliza una disposición jurídica determina, una cultura de cumplimiento de la legalidad. Dicha cultura representa el compromiso férreo de una persona jurídica de ser miembro responsable de nuestra sociedad, o, expresado de otra manera, el compromiso de cumplir con las obligaciones derivadas de ser un buen ciudadano corporativo"47.

\section{El caso español — después de la reforma de 2015-.}

Tras la modificación operada por la Ley Orgánica No 1/2015, del 30 de marzo de 2015, el artículo 31bis del CP reconoce efecto eximente de responsabilidad penal de la persona jurídica cuando aquella adoptó antes de la comisión del delito "modelos de organización y gestión que incluyen las medidas de vigilancia y control idóneas para prevenir delitos de la misma naturaleza o para reducir de forma significativa el riesgo de su comisión"48.

El legislador español tras hacer una distinción entre (i) los delitos cometidos por (a) los representantes legales, (b) quienes están au- torizados para tomar decisiones en nombre de la persona jurídica, (c) quienes ostentan facultades de organización y control dentro de la persona jurídica ${ }^{49}$; y, (ii) los delitos cometidos por quienes se encuentran sometidos a la autoridad de los sujetos indicados en el punto (i) y que se producen como consecuencia del incumplimiento grave de los deberes de supervisión, vigilancia y control que debería ser ejercido sobre ellos ${ }^{50}$; reconoce la posibilidad de exención de responsabilidad de la persona jurídica cuando se reúnen los requisitos previstos en el inciso 2 del artículo 31 bis del CP.

Pues bien, los requisitos necesarios para la exención de responsabilidad de la persona jurídica deben concurrir de forma copulativa antes de la comisión del delito ${ }^{51}$ y se distinguen en atención a los supuestos antes planteados.

Así para el supuesto de los sujetos indicados en el punto (i) se requieren los siguientes requisitos:

(i) la adopción y ejecución eficaz por parte de su administración de modelos de organización y gestión que comprendan medidas de prevención y control orientadas a la prevención de los delitos de la misma naturaleza de aquellos que darían motivo a la RRPJ;

47. GÓMEZ-JARA DÍEZ, Carlos. "Fundamentos de la responsabilidad penal de las personas jurídicas". En: BAJO FERNÁNDEZ, Miguel, FEIJOO SÁNCHEZ, Bernardo y GÓMEZ JARA DIEZ, Carlos. Tratado de responsabilidad penal de las personas jurídicas. Madrid: Civitas/ Thomson Reuters, 2012, p. 175. Sobre esta cuestión nos remitimos a lo indicado en líneas anteriores respecto a los programas de cumplimiento cosméticos.

48. De hecho, autores como GOENA VIVES, Beatriz. Responsabilidad penal y atenuantes en la persona jurídica. Madrid: Marcial Pons, 2017, p. 53, sostienen que uno de los "protagonistas" de la reforma del CP español del 2015 es el compliance.

49. Siempre que el delito sea cometido "en nombre o por cuenta" de la persona jurídica y "en su beneficio directo o indirecto".

50. Siempre que el delito sea cometido "en el ejercicio de actividades sociales y por cuenta y beneficio directo o indirecto" de la persona jurídica.

51. Si la acreditación de la concurrencia de estos elementos resulta parcial sus efectos serán meramente atentatorios de la pena. Los mismos efectos son reconocidos cuando los programas de cumplimiento son implementados después de la comisión del hecho delictivo y "antes del comienzo del juicio oral" —artículo 31 quater CP-. 
(ii) la función de supervisión del funcionamiento y cumplimiento del programa de cumplimiento en implementación se encuentre a cargo de (a) un órgano propio de la persona jurídica que posea autonomía de iniciativa y de control; $\mathrm{o}$, (b) tenga la obligación legal de supervisar los controles internos de la persona jurídica ${ }^{52}$;

(iii) el delito haya sido consecuencia de la elusión fraudulenta por parte de los autores individuales de los modelos de organización y prevención de la criminalidad; $y$,

(iv) el delito no haya sido consecuencia de la omisión o ejercicio insuficiente de las funciones de supervisión, vigilancia y control por parte del órgano a cargo del Compliance normativo.

Por otra parte, para los sujetos indicados en el apartado (ii) la exención de responsabilidad penal de la persona jurídica opera:

(i) Si se ha adoptado y ejecutado eficazmente un modelo de organización y gestión idóneo para prevenir delitos de la naturaleza del que ha sido cometido o para reducir significativamente el riesgo de su comisión ${ }^{53}$.

Sin embargo, la piedra angular sobre el cual reposa el sistema de exención de responsabilidad penal de la persona jurídica es la idea de adopción y ejecución de un modelo de organización y gestión idóneo para la prevención de delitos. Los programas de cumplimiento resultan, siempre que no se traten de programas de cumplimiento estéticos - make up programs - ${ }^{54}$, el escudo protector de las personas jurídicas en la medida que aquellos resulten eficaces para el propósito de prevención de delitos.

El legislador español ha procurado delinear normativamente -inciso 5 del artículo 31 bis del $\mathrm{CP}-{ }^{55}$ los elementos de un programa de cumplimiento eficaz al exigir en estos que:

(i) Identifiquen la actividades riesgosas desde la perspectiva jurídico penalque deben ser objeto de prevención;

(ii) Establezcan los protocolos o procedimientos que determinen el proceso de formación de voluntad de la persona jurídica en torno a la adopción y ejecución de decisiones orientadas a la prevención de los riesgos penales;

(iii) Cuenten con modelos de gestión a fin de contar con los recursos financieros que resulten adecuados para impedir la prevención de los delitos;

(iv) Establezca obligaciones de informar la existencia de posibles riesgos y de incumplimientos a los órganos a cargo del cumplimiento normativo;

(v) Establezca un sistema de reacción disciplinaria frente al incumplimiento de las medidas contenidas en los programas de cumplimiento; $y$,

(vi) Verifiquen el modelo de prevención y sus modificaciones cuando (a) se hayan

52. La responsabilidad del cumplimiento puede ser asumida, en el caso de personas jurídicas de pequeñas dimensiones por el propio órgano de administración.

53. Si la acreditación de la concurrencia de estos elementos resulta parcial sus efectos serán meramente atenuatorios de la pena.

54. ATAHUAMAN PAUCAR, Jhuliana. Op. Cit. p. 201.

55. Sobre estos elementos, SILVA SÁNCHEZ, Jesús María. Fundamentos del Derecho Penal de la Empresa, Segunda Edición. Madrid: Edisofer, 2016, pp. 366-378. 
observado infracciones trascendentes a sus disposiciones; $y$, (b) cuando se produzcan cambios en la organización, en la estructura de control o en el negocio o actividad que realicen que lo justifique.

\section{El caso peruano.}

En el caso peruano, la Ley 30424 —Ley que regula la responsabilidad administrativa de las personas jurídicas por el delito de cohecho activo transnacional- $\mathrm{y}$ el Decreto Legislativo 1352 - Decreto legislativo que amplía la responsabilidad administrativa de la persona jurídica-, que integra a la primera ley, reconocen también, aunque con diferencias terminológicas y técnicas, eficacia eximente de la responsabilidad de la persona jurídica ${ }^{56}$ a la implementación de modelos de prevención o programas de cumplimiento normativo.

Los artículos 17 a 19 de la Ley integrada regulan la "eximente por implementación de modelo de prevención". En su versión original - Ley 30424- dichos preceptos formaban parte de una Sección - la V- denominada "Modelo de prevención".

La primera cuestión a resaltar es su falta de referencia a la relación entre los autores del hecho criminal generador de la responsabilidad de la persona jurídica y su posición en la representación, dirección y administración de la persona jurídica. Con ello pareciera ignorarse el impacto que tendría -en el reconocimiento por parte de la persona jurídica de una cultura de cumplimiento- la intervención de los integrantes del directorio o la administración de la persona jurídica. Para el artículo 17 del texto integrado esto es completamente indiferente.

La exención de la responsabilidad de la persona jurídica se produce cuando antes de la comisión del delito se "adopta e implementa" en la orga- nización de la persona jurídica "un modelo de prevención adecuado a su naturaleza, riesgos, necesidad y características" y que comprenda "medidas de vigilancia y control idóneas para prevenir los delitos" - los incluidos dentro del alcance de la Ley - o "reducir significativamente el riesgo de su comisión" —artículo 17.1 de la Ley integrada-.

El legislador peruano ha tratado de proporcionar elementos para reconocer cuando se está frente a un "modelo de prevención adecuado". Sin embargo, la redacción utilizada por el legislador nacional ha sido poco afortunada pues al afirmar que "el modelo de prevención debe de contar con los siguientes elementos mínimos" -artículo 17.2- omitiendo utilizar el término "adecuado" podría dar lugar a dudas sobre sus alcances. Este estado de confusión parece incrementarse cuando observamos que el párrafo final del inciso 2 del artículo 17 de la Ley señala que "El contenido del modelo de prevención (...) se desarrolla en el Reglamento de la presente Ley".

En efecto, podría pensarse - con esta redacción-que se hace referencia únicamente a los elementos de cualquier modelo de prevención y no al modelo de prevención adecuado - esto es, aquél con eficacia eximente de responsabilidad de la persona jurídica-. Esta lectura tendría la consecuencia práctica de permitir que el Fiscal o el Juez recurran a criterios de interpretación restrictivos de la eximente por implementación de modelo de prevención.

Si la Ley hace referencia a las condiciones mínimas de -cualquier- modelo de prevención -esto es, se haría referencia al génerola interpretación lógica en este caso llevaría a entender que la especie - conformada por los programa de cumplimiento adecuados- tendría elementos adicionales.

56. No ingresaré al análisis de la naturaleza jurídica de la responsabilidad impuesta a la persona jurídica por la Ley 30424; sobre esta cuestión, decantándose en favor de la naturaleza administrativa de la ley, ASTUDILLO MEZA, Guillermo. "Hacia la implementación de los programas de cumplimiento (Compliance) en el Perú". En: Anuario de Derecho Penal. Temas de Derecho Penal Económico: Empresa y Compliance. Lima: Fondo Editorial PUCP, 2016, p. 238. 
Una interpretación sistemática, sin embargo, permite superar estas deficiencias en la redacción y sostener que la referencia legal se dirige exclusivamente a los modelos de prevención adecuados. El nomen iuris utilizado por el legislador para dar título al artículo 17 permite reconocer con claridad el telos de la ley.

\section{El modelo de prevención adecuado.}

Zanjada la cuestión, tenemos que un modelo de prevención adecuado, conforme a nuestra ley, es aquél que, cuanto menos:

(i) Cuenta con un agente responsable de la prevención de los delitos -es decir un oficial de cumplimiento o Compliance officer- que goce de autonomía en el ejercicio de sus funciones y que haya sido designado por los responsables máximos de la administración de la persona jurídica. El encargado del cumplimiento normativo puede ser el propio órgano de administración en caso de micro, pequeñas y medianas empresas;

(ii) Identifica, evalúa y mitiga riesgos con el objetivo de prevenir la comisión de los delitos comprendidos en la Ley a través de la persona jurídica. El Proyecto de Reglamento de la Ley desarrolla dichos aspectos con carácter pormenorizado -la identificación del riesgo se encuentra desarrollada en los artículos 13 a 17, la evaluación de riesgos se encuentra comprendida en los artículos 18 a 21, en tanto que la mitigación de riesgos se encuentra desarrollada en los artículos 22 a 24一;

(iii) Implementa procedimientos de denuncia;

(iv) Difunde y capacita periódicamente respecto al modelo de prevención y su contenido; $y$,

(v) Evalúa y monitorea continuamente el modelo de prevención.
Ahora, resulta extraño que, no obstante fijarse el contenido mínimo del modelo de prevención adecuado con eficacia eximente de responsabilidad de la persona jurídica haya el legislador recurrido a un reenvío normativo externo hacia el Reglamento, aun inexistente, de la Ley. Con esto, no solo se deja en stand by el rigor de la eximente, sino que revela el claro desconocimiento del legislador peruano de las cuestiones propias del Compliance y sus contenidos.

En efecto, cuando el legislador peruano recurre al reenvío hacia el reglamento - repito, aún inexistente- parece reconocer implícitamente su falta de capacidad para aprehender —en el sentido de "captar" o "capturar" — los contenidos, dinámicos y de especial técnica, del Compliance.

Esta incapacidad se hace más notoria cuando observamos las referencias a la aplicación de la eximente por implementación de programas de cumplimiento en el caso de micro, pequeñas y medianas empresas. En estos casos, refiere la Ley, "el modelo de prevención será acotado a su naturaleza y características y solo debe contar con alguno de los elementos mínimos antes señalados". Se omite, sin embargo, mencionar cuál —no cuáles porque la Ley utiliza el singular en su redacción- sería ese elemento mínimo y no queda claro si este elemento sólo comprende aquellos mencionados en la Ley o si incluye también aquellos que serán incluidos en el Reglamento.

Con esto ciertamente no se quiere cuestionar la capacidad del legislador penal sino resaltar algunas circunstancias que provocan una suerte de resistencia natural a la asimilación de estos conceptos.

La primera de estas circunstancias seria la extrema complejidad de una materia -Compliance- en la que intervienen, además de abogados, contadores, economistas y auditores. De hecho, los casos criminales instaurados en relación a las quiebras de Enron y Worldcom tuvieron como eje central el análisis de la actuación de los diversos profesionales desde sus diversas posiciones - como auditores internos $y$

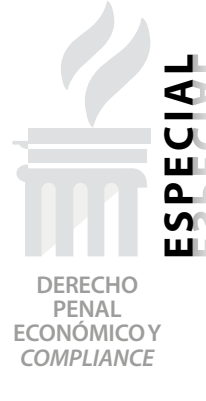

ran

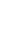


externos, analistas bursátiles, abogados, agencias de calificación crediticia- ${ }^{57}$.

La segunda circunstancia a mencionar sería la aún persistente imprecisión conceptual en esta parcela del conocimiento. En este plano conviene recordar asimismo la existencia de una variedad de conceptos cercanos o compatibles con el Compliance. Así, por ejemplo Goena Vives, destaca la proximidad con las expresiones $\mathrm{Bu}$ siness Ethics, Corporate codes, Risk management, Value management, Corporate governance, y Codes of conduct, circunstancia que da cuenta de la complejidad de la materia ${ }^{58}$.

Una tercera circunstancia es la ubicación natural del Compliance en extramuros del Derecho Penal. En efecto, la idea de control empresarial propia del cumplimiento normativo tiene carta de naturaleza en el ámbito del Derecho de Sociedades ${ }^{59}$.

Una cuarta dificultad se encuentra asociada al carácter contextual del Compliance. En efecto, la forma en que el Compliance opera variará no solo en función al tipo de negocio del que se trate sino también en relación al país del que provenga la persona jurídica o del tipo de actividad que desempeñe ${ }^{60}$.

Una quinta dificultad se relación con el origen territorial del Compliance. La doctrina es coincidente en reconocer que el Compliance surge en el sistema federal de los EEUU ${ }^{61}$, circunstancia que dificulta aún más su asimilación a nuestro sistema jurídico penal. Un ejemplo manifiesto de esta cuestión guarda relación precisamente con una de las temáticas abordadas en este ensayo - la del efecto de la implementación de un programa de cumplimiento efectivo-. Mientras en nuestros países se viene reconociendo efectos eximentes o atenuantes de responsabilidad de las personas jurídicas, en el sistema norteamericano la implementación de un effective corporal Compliance program no necesariamente impacta en la responsabilidad penal de la persona jurídica, pues aquello depende de la clase de delito del cual se trate ${ }^{62}$.

57. Al respecto: COFFEE JR., John C. Gatekeepers. The professions and Corporate Governance. New York: Oxford University Press, 2006, pp. 24-54. En lengua hispana, ver OLCESE SANTONYA, Aldo. Teoría y práctica del buen gobierno corporativo. Madrid: Marcial Pons, 2005, pp. 239 y ss, quien además repasa los casos Global crossing, Vivendi y Parmalat; en la doctrina peruana: VASSALLO SAMBUCETI, Efrain. "La avaricia criminalizada: Delincuencia de cuello y corbata". En: PÉREZ BEJARANO, Alfredo (coord.). El Derecho Penal Económico. Cuestiones fundamentales y temas actuales. Lima: Ara, 2011, pp. 107-110 — haciendo referencia al caso Enron-.

58. GOENA VIVES, Beatriz. Op. Cit., pp. 329-331.

59. Lo que explica la posición de autores como QUINTERO OLIVARES, Gonzalo. "La reforma del régimen de responsabilidad penal de las personas jurídicas". En QUINTERO OLIVARES, Gonzalo (Director). Comentario a la reforma penal de 2015. Navarra: Aranzadi, 2015, p. 81, que sostienen que es en dicha parcela del ordenamiento jurídico donde se encuentra regulada la obligación de control en el ámbito empresarial y que su trascendencia se relaciona exclusivamente con la responsabilidad civil ex delito.

60. En ese sentido, HANSMANN, Henry y KRAAKMAN, Reinier. "The end of history for corporate law". En GORDON, Jeffrey y ROE, Mark (Ed.). Convergence and persistence in Corporate Governance. New York: Cambridge University Press, 2004, p. 33 — resaltando la diversidad de enfoques dependiendo del origen geográfico de la persona jurídica一; también REYNA ALFARO, Luis. "La responsabilidad penal del compliance officer: Algunas consideraciones iniciales sobre el nuevo delito de omisión culpas de comunicación de operaciones sospechosas". En Anuario de Derecho Penal Económico y de la Empresa № 3. Lima: CEDPE, 2015, pp. 273 y ss. —destacando el carácter contextual del compliance en relación a las microfinancieras-.

61. Así, entre otros, ATAHUAMÁN PAUCAR, Jhuliana. Op. Cit., pp. 199 y ss.; GARCÍA CAVERO, Percy. Criminal Compliance. Lima: Palestra, 2014, pp. 26-27.

62. En ese sentido, STRADER, Kelly. White collar crime. San Francisco: LexisNexis, 2011, pp. $22-23$ y 355-356, quien menciona el precedente United States v. Hilton Hotels Corp. 
Pareciese que la propia ley reconoce la incapacidad de los operadores del sistema de administración de justicia penal para reconocer las condiciones que debe reunir un modelo de prevención de la criminalidad por parte de las personas jurídicas. Al menos así pareciese en relación a la actuación del Ministerio Público.

En efecto, al introducir la exigencia - a manera de requisito de procedibilidad- de contar antes de la formalización de investigación preparatoria con un informe técnico por parte de la Superintendencia del Mercado de Valores - artículo 18 de la Ley - cuyo objeto sea analizar la implementación y funcionamiento del modelo de prevención, pareciese que el legislador entendiese que el Ministerio Público requiere necesariamente —de allí su condición sine qua non- del apoyo de expertos ${ }^{63}$. Este requisito - conforme apreciaremos más adelante- pareciese establecer una carga probatoria sobre el órgano acusador que debería recaer sobre la persona jurídica que la alega — como es propio de toda circunstancia impeditiva del ejercicio de la acción penal-.

En contra del reenvío juega no solo el hecho que este se dirige hacia un reglamento aún no existente sino también la ausencia de una regulación general de los programas de cumplimiento. En efecto, aunque es cierto que el Compliance y los Compliance programs tienen cobertura y regulación en ciertas parcelas específicas de la actividad económica ${ }^{64}$, el hecho que no posean una regulación general -comprehensiva de todos sus ámbitos - y que en aquellos donde esa regulación existe se produzcan posibles inconsistencia puede provocar el posible desvanecimiento de los posibles efectos positivos de recurrir a la técnica del reenvío - de ganar en seguridad jurídica al confiar a una norma extra penal especializada la delimitación de los elementos de un modelo de prevención-.

Es posible que en su elaboración el legislador peruano haya tomado en consideración el modelo español que tras la reforma del 2015 - Ley Orgánica 1/2015 - optó por proponer en el propio texto del CP español los elementos que debe contener un modelo de prevención eximente de responsabilidad respondiendo de este modo a las demandas en ese sentido fundadas en criterios de seguridad jurídica — de la persona moral — ${ }^{65}$ que

63. Prescindimos aquí de realizar mayores consideraciones respecto a la conveniencia de recurrir a la SMV como el experto competente en esta materia. Sin embargo, es de advertir la posible relación de la referencia legislativa peruana al ente regulador del mercado de valores con dos circunstancias puntuales (i) el hecho de que fuese la Securities and Exchange Commission-SEC, el análogo norteamericano de la SMV, la que desentrañara e impulsara las persecuciones penales iniciadas entre los años 2001 y 2002 contra Enron y WorldCom —las dos quiebras empresariales más grandes de la historia norteamericana- y que tenían como eje central las fallas de los sistemas de control interno y externo de las empresas — véase al respecto COFFEE JR., John. Op. Cit., pp. 15 y ss.—; y, (ii) el hecho que fuera el órgano de supervisión bursátil —antes CONASEV, hoy SMV — la que introdujera la noción de buen gobierno corporativo en nuestro país a través de los "Principios de buen gobierno para las sociedades peruanas" — 2002, actualizado el 2013 con el nombre de "Código de Buen Gobierno Corporativo para las Sociedades Peruanas"—; así GARCÍA CAVERO, Percy. Criminal Compliance. Lima: Palestra, 2014, pp. 28-29.

64. Destacando en España la ausencia de regulación general del Compliance, ALONSO GALLO, José. "Capítulo V: Los programas de cumplimiento". En: DÍAZ-MAROTO Y VILLAREJO, Julio (Director). Estudios sobre las reformas del Código Penal (Operadas por las LO 5/2010, de 22 de junio, y 3/2011, de 28 de enero). Madrid: Civitas, 2011, p. 152; también AROCENA, Gustavo. "¿De qué hablamos cuando hablamos de criminal compliance?". En: COCA VILA, Ivo, URIBE MANRIQUEZ, Alfredo, ATAHUAMAN PAUCAR, Jhuliana y REYNA ALFARO, Luis (coords.). Compliance y responsabilidad de las personas jurídicas. México: Flores Editor, 2016, p. 1; por otra parte, resaltando la diferencia del análisis de la existencia de modelos de prevención entre los sectores regulados y los no regulados, SILVA SÁNCHEZ, Jesús María. Fundamentos del Derecho Penal de la Empresa, Segunda Edición. Madrid: Edisofer, 2016, pp. 408-409.

65. En ese sentido: DE LA MATA BARRANCO, Norberto. "La actuación conforme a protocolos de prevención de delitos como causa de exención de responsabilidad penal". En DE LA CUESTA ARZAMENDI, José Luis (Director). Responsabilidad penal de las personas jurídicas. Navarra: Thomson Reuters/Aranzadi, 2013, p. 249; AYALA DE LA TORRE, José María. Compliance. Madrid: Francis Lefebvre, 2016, p. 79. 
exigían taxatividad en el desarrollo de una cuestión central en la configuración de un sistema de responsabilidad penal de la persona jurídica ${ }^{66}$; no obstante, la importación de la ley penal resultó en este caso defectuosa.

Mayor rigor técnico habría tenido una redacción que prescindiendo del reenvío hubiera confiado la configuración de la eximente exclusivamente a elementos normativos valorativos - expresadas en el término "modelo de prevención adecuado" conforme nuestra Leyque permitan al Juez y Fiscal analizar, caso por caso, la instalación de una cultura de cumplimiento dentro de las personas jurídicas. De esta manera se evita encorsetar a los operadores del sistema de administración de justicia penal y se permite interpretaciones de la ley que resulten más acordes con el dinamismo propio de esta materia.

Ahora, esta opción tampoco debería generar dudas respecto a la capacidad del Juez o el Fiscal de proceder a este tipo de análisis. Como señala Ortiz de Urbina Gimeno en la determinación de la implementación de un modelo de prevención adecuado: "el grado de complejidad es similar al existente en la determinación de la infracción del deber de cuidado fuera de los ámbitos fuertemente normados extra-penalmente, como el tráfico rodado o el medio ambiente. En estos casos los operadores jurídicos han de concretar para el caso las expectativas de comportamiento basadas en estándares de diligencia media, y éste deberá ser así el camino a seguir con los planes de prevención de delitos ${ }^{1167}$.

\section{VALIDACIÓN CRIMINOLÓGICA DEL COMPLIANCE COMO SENDERO HACIA EL CUAL PODRÍA EVOLUCIONAR LA DOGMÁTICA DE LA RPPJ}

La capacidad de rendimiento del Compliance como categoría trascendente en la determinación de la RPPJ puede tener, asimismo, justificación empírica a partir de los desarrollos provenientes de la criminología que han destacado la trascendencia de la subcultura empresarial y los objetivos de la empresa en el ámbito del corporate crime.

En efecto, tal como reconoce Sally S. Simpson ${ }^{68}$,

66. Considerando que dicha responsabilidad penal respondería al defecto de organización de la persona jurídica expresado en la ausencia de una organización fundada en el cumplimiento de la ley: véase GÓMEZ-JARA DÍEZ, Carlos. La culpabilidad penal de la empresa. Madrid: Marcial Pons, 2005, pp. 48 y ss. - estructurando el fundamento material de la culpabilidad a partir de la idea del "ciudadano fiel al derecho" y en relación a la idea de "buen ciudadano corporativo"-; BACIGALUPO ZAPATER, Enrique, Op. Cit., pp. 100-101; FEIJOÓ SÁNCHEZ, Bernardo. EI delito corporativo en el Código Penal Español. Madrid: Civitas, 2015 pp. 70 y ss.; GÓMEZ TOMILLO, Manuel. Compliance penal y política legislativa. Valencia: Tirant lo Blanch, 2016, p. 30; GÓMEZ TOMILLO, Manuel. Introducción a la responsabilidad penal de las personas jurídicas, Segunda Edición. Navarra: Aranzadi, 2015, pp. 134-143. Incluso a nivel jurisprudencial la Sentencia del Pleno de la Sala II del Tribunal Supremo español del 29 de febrero de 2016 ha reconocido que el núcleo de la responsabilidad penal de la persona jurídica es: "la ausencia de las medidas de control adecuadas para la evitación de la comisión de delitos"; al respecto, GÓMEZ-JARA DíEZ, Carlos. El Tribunal Supremo ante la Responsabilidad Penal de las Personas Jurídicas. Navarra: Aranzadi, 2017, pp. 70 ss.

67. ORTIZ DE URBINA GIMENO, Íñigo. "Capítulo III: Responsabilidad penal de las personas jurídicas y programas de cumplimiento empresarial -'Compliance programs'-". En: GOÑI SEIN, José Luis (Director). Ética empresarial y Códigos de conducta. Madrid: La Ley, 2011, p. 131.

68. SIMPSON, Sally. Corporate crime, law and social control. New York: Cambridge University Press, 2002, p. 7. No debe soslayarse la importancia de los datos propuestos por Edwin Sutherland en su obra fundamental White collar crime en la que describe el modo en que tres empresas American Smelting and Refining Company, Unites States Rubber Company y The Pittsburg Coal Company subsistieron por décadas incurriendo en infracciones a la libre competencia y detalla cómo es que su finalidad económica -dominar el mercado- guió las diversas decisiones de sus agentes; véase SUTHERLAND, Edwin. El delito de cuello blanco, traducción de Laura Belloqui. Buenos Aires: BdeF, 2009, pp. 33-62. 
la actuación de los agentes corporativos - directores, gerentes, administradores, etc. - se desarrolla tomando en consideración los objetivos de la empresa - mantener ganancias, administrar un mercado incierto, reducir costos fijos, eliminar la competencia- que llevan a que las empresas contaminen el medio ambiente, incurran en fraudes financieros, reduzcan las condiciones de seguridad de sus trabajadores, comercialicen productos defectuosos $^{69}$; en ese contexto, la actuación de los agentes de las empresas se encuentran apoyadas por las normas operacionales y su subcultura organizacional ${ }^{70}$.

Esta autora ha reconocido cómo es que las percepciones sobre las necesidades de la organización empresarial tienen impacto - acreditado empíricamente - sobre las decisiones delictivas de los agentes corporativos y en las que las necesidades individuales de los empleados de la empresa tienen muy poca significación ${ }^{71}$. $Y$ es que, como señalan Rosenfeld y Messner la economía promueve ciertos valores e impone ciertas pautas de actuación que debilitan la regulación institucional ${ }^{72}$.
Los corporate crimes ocurren por tanto dentro de un contexto organizacional específico. Aunque la empresa es un todo orgánico ${ }^{73}$, existen dentro de sus diversas unidades una serie de culturas y subculturas en cuyo ámbito se produce la socialización de los agentes corporativos influenciada, como es evidente, por los objetivos empresariales ${ }^{74}$.

Precisamente por esa razón Simpson reconoce que los efectos de prevención intimidatoria en el contexto empresarial se encuentran condicionados por cómo los agentes corporativos experimentan y expresan los imperativos morales de su ambiente laboral y por cómo las necesidades organizacionales son formuladas e introducidas en las decisiones gerenciales ${ }^{75}$.

Ello lleva a reconocer que la cultura y organización empresarial generen una mente grupal - group mind - ${ }^{76}$ a la que los agentes corporativos se amoldan lo que determina que reaccionen en automático, siguiendo sus predisposiciones, sus códigos de conducta, las estructuras de poder, sus reglas de organización

69. Como sostiene NELKEN, David. "White collar and corporate crime". En MAGUIRE, Mike- Morgan, ROD- REINER, Robert. The Oxford Handbook of Criminology, Cuarta Edición. Oxford: Oxford University Press, 2007, pp. 744, en el business environment el objetivo es mantener e incrementar las ganancias incluso en las circunstancias más difíciles.

70. Similares BRODOWSKI, Dominik, ESPINOZA DE LOS MONTEROS DE LA PARRA, Manuel, TIEDEMANN, Klaus y VOGEL, Joachim (Eds.). Regulating corporate criminal liability. Nueva York: Springer, 2014, p. 3.

71. SIMPSON, Sally. Op. Cit., p. 7.

72. ROSENFELD, Richard y MESSNER, Steven. Crime and the economy. Londres: Sage, 2013, p. 63.

73. Obsérvese aquí la relación existente entre esta idea — la de la existencia de una cultura empresarial- con la teoría organicista de la persona jurídica de Gierke que se sostiene en la idea de que la persona jurídica es un organismo social y que es objetivo del derecho ordenar y penetrar su estructura interna y su vida interior; sobre el contenido de dicha teoría: BACIGALUPO ZAPATER, Enrique, Op. Cit., p. 84.

74. PALMER, Donald. Normal organizational wrongdoing. A critical analysis of theories of misconduct in and by organizations. New York: Oxford University Press, 2012, p. 7. Similar, SIEBER, Ulrich. Op. Cit., p. 96; MONTANER FERNÁNDEZ, Raquel. Op. Cit., p. 148; BAIGUN, David. Op. Cit., p. 45.

75. SIMPSON, Sally. Op. Cit., p. 9; similar ENGELHART, Marc. Op. Cit., p. 66.

76. MENTOVICH, Avital y CERF, Moran. "A psychological perspective on punishing corporate entities". En: BRODOWSKI, Dominik. ESPINOZA DE LOS MONTEROS DE LA PARRA, Manuel, TIEDEMANN, Klaus, VOGEL, Joachim (Eds.), Regulating corporate criminal liability. Nueva York: Springer, 2014, p. 37. 
y sus protocolos ${ }^{77}$. Estas circunstancias llevan a que autores como Palmer sostengan que los agentes corporativos, en el contexto de las estructuras empresariales, actúan mindless, en automático ${ }^{78}$.

En ese orden de ideas, una cultura empresarial estructurada en la obtención de réditos económicos condicionará a sus agentes a que ignoren los contextos normativos y de rigor de la ley. El interés por obtener réditos económicos en los agentes de la empresa le llevarán a utilizar cualquier medio que consideren útil sin importar su sentido ético, moral o legal ${ }^{79}$.

Pero el impacto de la organización y estructura empresarial sobre los agentes corporativos van incluso más allá de la simple influencia asociada a los objetivos de la empresa, sino que se relaciona a la ocasional ambigüedad de la actuación empresarial en la que los discursos internos -incremento del valor-son completamente opuestos a los discursos externos - cumplimiento de la ley-. No extra- ña, en ese contexto, que David Nelken haya calificado a los managers como una especie de animales camaleónicos alimentados por la ambigüedad moral y la falta de certeza organizacional ${ }^{80}$. Con esta idea se destaca precisamente cómo es que la falta de políticas y códigos empresariales definidos afecta el sentido de las actividades de los agentes corporativos.

Los efectos de esta ambigüedad de las políticas y códigos empresariales se hacen más intensos en escenarios como los regulatorios económicos en los que existe cierta dicotomía respecto al carácter efectivamente ilegal de ciertas conductas. En el ámbito de la actividad empresarial es ciertamente dificultoso reconocer con claridad las fronteras entre un comportamiento agresivo pero lícito de aquél que supera dichas barreras ${ }^{81}$.

El proceso de toma de decisiones en el entorno empresarial opera, vistas así las cosas, de forma completamente distinta a cómo este opera cuando la toma de decisión se realiza indivi-

77. PALMER, Donald. Op. Cit., p. 15. Esta idea resulta cercana a la de actitud criminal colectiva sostenida por SCHÜNEMANN, Bernd. "Las prescripciones sobre la autoría en la Ley Boliviana sobre la base de las modificaciones al Código penal del 10 de marzo de 1997 y sus consecuencias para la responsabilidad penal de los porganos de la empresa ¿Un modelo para latinoamérica?", traducción de Mariana Sacher. En: REYNA ALFARO, Luis (Coord.). Nuevas tendencias del Derecho penal económico y de la empresa. Lima: Ara, 2005, p. 514; HURTADO POZO, Jose y MEINI MÉNDEZ, Iván. "Las personas jurídicas frente al Derecho Penal peruano". En: HURTADO POZO, José; DEL ROSAL BLASCO, Bernardo; SIMONS VALLEJO, Rafael (coords.). La responsabilidad criminal de las personas jurídicas. Una perspectiva comparada. Madrid: Tirant lo Blanch, 2001, p.77.

78. PALMER, Donald. Op. Cit., p. 16.

79. No resulta complicado, en este punto, reconoce la influencia del pensamiento de Merton y la teoría de la anomia; al respecto ROSENFELD, Richard y MESSNER, Steven. Crime and the economy. Londres: Sage, 2013, p. 64.

80. NELKEN, David. "White collar and corporate crime". En MAGUIRE, Mike- Morgan, ROD- REINER, Robert. The Oxford Handbook of Criminology, Cuarta Edición. Oxford: Oxford University Press, 2007, pp. 742. La ambiguedad moral hace - señala Nelken citando a Punch - que todo sea too messy not to say dirty — muy desordenado por no decir sucio-.

81. En ese sentido GREEN, Stuart. Op. Cit., p. 45. Un ejemplo especialmente significativo de la ausencia de claridad respecto al sentido antijurídico de ciertos comportamientos se aprecia respecto al insider trading que es visto por muchos académicos como un comportamiento que hace que el mercado se haga más eficiente; así GREEN, Stuart. Op. Cit., pp. 236 y ss.; sobre esta cuestión, REYNA ALFARO, Luis Miguel. "El abuso de información privilegiada en el Derecho penal peruano". En RUIZ RODRÍGUEZ, Luis Ramón y REYNA ALFARO, Luis Miguel (coordinadores). La regulación penal del mercado de valores (Estudio de Derecho peruano y español). Lima: Jurídica Portocarrero, 2001, p. 27. 
dualmente ${ }^{82}$. No extraña que Palmer reconozca que no se trata sólo de examinar las bad apples sino de observar también los bad barrels ${ }^{83}$.

Los hallazgos de la criminología y la sociología en este ámbito, sin embargo, van más allá. En efecto, no es que la organización empresarial sólo tenga impacto en el corporate crime a través de la influencia que la cultura empresarial tiene en el proceso de toma de decisiones corporativas, sino que su impacto se manifiesta en términos causales: La organización empresarial facilita y contribuye con la realización del delito ${ }^{84}$.

\section{CONCLUSIONES}

A través del presente trabajo se ha pretendido introducir ciertos matices novedosos en la ya bastante prolífica discusión respecto a la capacidad de rendimiento del Compliance como criterio determinante de la RPPJ. Es precisamente la introducción de estos matices la que evitará que el Compliance se transforme en una simple buzz word, en un concepto de moda que, al final de cuentas, carezca de contenido real ${ }^{85}$.

En ese contexto, el Compliance y los programas de cumplimiento normativo constituyen mecanismos orientados a instrumentalizar una cultura corporativa en el que el cumplimiento de la ley constituya un valor que se impregna en los diversos componentes de la estructura empresarial. El efecto preventivo del Compliance se puede reconocer a partir de los hallazgos de la criminología que permite advertir cómo es que la cultura empresarial impacta en las personas naturales que interactúan dentro de la estructura empresarial.

Este dato -impacto preventivo de la cultura de cumplimiento- constituye un dato empírico que podría servir para fundamentar propuestas orientadas a conceder efectos atenuantes o eximentes de responsabilidad penal a la implementación efectiva de programas de cumplimiento.

82. De hecho, esta autora norteamericana destaca la escasa trascendencia de la amenaza de la pena en la prevención del corporate crime y el mayor impacto que tienen las consecuencias económico reputacionales en la persona jurídica, dado que las empresas se encuentran orientadas hacia el futuro y eso provoca su preocupación por los efectos reputacionales que acarrea la comisión de un delito; al respecto Simpson: Corporate crimes, 52

83. PALMER, Donald. Op. Cit., p. 7.

84. SIMPSON, Sally. Op. Cit., p. 54.

85. Riesgo advertido por ROTSCH, Thomas. "Criminal Compliance". En: Indret. Revista para el análisis del derecho. Disponible en: $<$ http://www.indret.com/pdf/876a.pdf $>$. 